\title{
Racemic epinephrine compared to salbutamol in hospitalized young children with bronchiolitis; a randomized controlled clinical trial [ISRCTN4656 I076]
}

\author{
Joanne M Langley*1,2,3, Michael B Smith4, John C LeBlanc ${ }^{2,3,5}$, \\ Heather Joudrey ${ }^{1}$, Cecil R Ojah ${ }^{2,6}$ and Paul Pianosi ${ }^{7}$
}

\begin{abstract}
Address: ${ }^{1}$ Clinical Trials Research Centre, Dalhousie University, Halifax, Canada, ${ }^{2}$ Departments of Pediatrics, Dalhousie University, Halifax Canada, ${ }^{3}$ Departments of Community Health and Epidemiology, Dalhousie University, Halifax, Canada, ${ }^{4}$ Department of Pediatrics, Queen's University Belfast and Craigavon Area Hospital, Craigavon, Northern Ireland, ${ }^{5}$ Department of Psychiatry, Dalhousie University, Halifax, Canada, ${ }^{6}$ Saint John Regional Hospital, Atlantic Health Sciences Corporation, Saint John, Canada and ${ }^{7}$ Division of Allergy, Immunology and Pulmonology, Department of Pediatric and Adolescent Medicine, Mayo Clinic Rochester, MN, USA

Email: Joanne M Langley* - joanne.langley@dal.ca; Michael B Smith - msmith@cahgt.n-i.nhs.uk; John C LeBlanc - john.leblanc@dal.ca; Heather Joudrey - heather.merry@dal.ca; Cecil R Ojah - ojace@reg2.health.nb.ca; Paul Pianosi - pianosi.paolo@mayo.edu

* Corresponding author
\end{abstract}

Published: 05 May 2005

BMC Pediatrics 2005, 5:7 doi:10.1 |86/|47|-243|-5-7
Received: 24 November 2004

Accepted: 05 May 2005

This article is available from: http://www.biomedcentral.com/|47|-243 I/5/7

(C) 2005 Langley et al; licensee BioMed Central Ltd.

This is an Open Access article distributed under the terms of the Creative Commons Attribution License (http://creativecommons.org/licenses/by/2.0), which permits unrestricted use, distribution, and reproduction in any medium, provided the original work is properly cited.

\begin{abstract}
Background: Bronchiolitis is the most common cause of lower respiratory tract illness in infancy, and hospital admission rates appear to be increasing in Canada and the United States. Inhaled beta agonists offer only modest short-term improvement. Trials of racemic epinephrine have shown conflicting results. We sought to determine if administration of racemic epinephrine during hospital stay for bronchiolitis improved respiratory distress, was safe, and shortened length of stay.
\end{abstract}

Methods: The study was a randomized, double-blind controlled trial of aerosolized racemic epinephrine compared to salbutamol every one to 4 hours in previously well children aged 6 weeks to $\leq 2$ years of age hospitalized with bronchiolitis. The primary outcome was symptom improvement as measured by the Respiratory Distress Assessment Instrument (RDAl); secondary outcomes were length of stay in hospital, adverse events, and report of symptoms by structured parental telephone interview one week after discharge.

Results: 62 children with a mean age of 6.4 months were enrolled; $80 \%$ of children had Respiratory Syncytial Virus (RSV). Racemic epinephrine resulted in significant improvement in wheezing and the total RDAI score on day 2 and over the entire stay $(p<0.05)$. The mean LOS in the epinephrine arm was 2.6 days $(95 \% \mathrm{Cl} 2,3.2)$ v. 3.4 days in those in the salbutamol group $(95 \% \mathrm{Cl} 2.6,4.2)(\mathrm{P}$ $>0.05$ ). Adverse events were not significantly different in the two arms. At one week postdischarge, over half of parents reported that their child still had a respiratory symptom and $40 \%$ had less than normal feeding.

Conclusion: Racemic epinephrine relieves respiratory distress in hospitalized infants with bronchiolitis and is safe but does not abbreviate hospital stay. Morbidity associated with bronchiolitis as identified by parents persists for at least one week after hospital discharge in most infants. 


\section{Background}

Bronchiolitis accounts for up to $60 \%$ of all lower respiratory tract illness in the first year of life [1] and up to $32 \%$ of hospitalizations for lower respiratory tract illness in this age group [2]. The incidence of hospitalisation for bronchiolitis in infancy has increased in both the United States [3] and Canada [4] in the last two decades, and a $100 \%$ increase in first time hospitalisation for lower respiratory tract illness in children under two years has been noted in northern Europe [5].

Bronchiolitis is characterized by tachypnea and wheezing due to obstruction of small airways, and therefore treatment has often included use of beta and alpha agonists delivered by aerosol in addition to supportive care. A systematic review of randomised clinical trials of the efficacy of beta-agonist aerosols suggests they offer only modest short term improvement [6]. Alpha agonist stimulation of the sympathetic nervous system would be expected to reduce capillary leakage by constricting precapillary arterioles, reducing hydrostatic pressure and consequently bronchial mucosal edema [7]. Since Wohl and Chernick first suggested this intervention in 1978 [8], multiple studies and systematic reviews [9-11] have been published. While there is evidence that acute symptoms of bronchiolitis measured in the short term may improve with epinephrine, these reviews have called for more studies assessing longer-term outcomes such as duration of stay, and that are clinically relevant to parents, clinicians and the health care system.

We report a randomised controlled trial of aerosolised epinephrine compared to salbutamol throughout hospital stay in infants with bronchiolitis to assess daily clinical improvement (respiratory distress, feeding), length of hospital stay and adverse events, and outcomes by parental report one week after discharge to the community.

\section{Methods}

This study was a randomized, double blind controlled trial of racemic epinephrine (Vaponefrin solution 2.25\%, Aventis Pharma Inc, Laval, PQ) compared to control (salbutamol, Ventolin, GlaxoSmithKline Inc., Mississauga, $\mathrm{ON}$ ) in children requiring hospitalization for management of bronchiolitis.

\section{Patient population}

Eligible children were aged greater than 6 weeks to $\leq 2$ years with a clinical diagnosis of bronchiolitis by the admitting physician. Wheezing had to be present on physical examination and was defined as a high-pitched, musical, continuous respiratory sound. Only patients admitted for management of bronchiolitis were eligible. The parent or guardian had to be able cooperate with study requirements (ability to speak, read and write English, have a tel- ephone at home and not expected to move within the next month). The participating institutions were the IWK Health Centre in Halifax, Nova Scotia and the Saint John Regional Hospital (SJRH) in Saint John, New Brunswick. The IWK is a university-affiliated primary and tertiary-care pediatric hospital with an urban population of 300,000 and is a referral center for the Maritime provinces (population 2 million) of Canada. SJRH serves a rural-urban population of 200,000 .

Children were not eligible for enrollment if they had had a previous diagnosis of asthma, were critically ill, or had chronic pulmonary or cardiac disease. Other exclusion criteria included: allergy to sodium metabisulfite, presence of tachycardia exceeding 200 beats per minute, or use of glucocorticoids, sympathomimetic amines or monoamine oxidase inhibitor therapy.

Informed consent was obtained from the parent or guardian prior to enrolment. The protocol was approved by the Ethics Review Board at both participating institutions.

\section{Study procedures}

Study enrolment occurred in sequential winter respiratory seasons (November to April) from 1999 to 2002. Families were approached regarding study participation in the emergency department or within 24 hours of admission. Research nurses were available to enroll patients between 8 am and $8 \mathrm{pm}$.

Treatment allocation was determined by randomization, performed in blocks of four by the pharmacy department using a computer-generated random numbers table. Study drug was packaged in identical multidose vials labeled "study drug" with a code number. Both salbutamol and racemic epinephrine are clear, colorless liquids that are indistinguishable [12]. Participants were allocated to racemic epinephrine, $0.5 \mathrm{mls}$ of $2.25 \%$ (Vaponefrin solution, Aventis Pharma, Montreal Quebec) or salbutamol respirator solution (Pharmel Inc., Montreal, Canada) by aerosol. Study drug was administered every one to four hours or more frequently at the request of the attending physician. Study drug was delivered by a wall flowmeter-nebulizer with face mask (Hospitak Inc., Farmingdale, NC) with oxygen at 5 to $7 \mathrm{~L} / \mathrm{min}$. A standard order sheet was used to ensure consistency of trial methodology. Salbutamol was given in $3 \mathrm{ml}$ normal saline at a dosage of $1.5 \mathrm{mg}$ for children weighing more than $10 \mathrm{~kg}$, $1.25 \mathrm{mg}$ for children $>6 \mathrm{~kg}$ and $<10 \mathrm{~kg}$, and $0.75 \mathrm{mg}$ for those weighing less than 6 kgs. The heart rate was measured continuously during each aerosol and for one hour after. The heart rate, vomiting, presence of tremors or pallor were recorded in the health record by the bedside nurse at the end of every aerosol and one hour post aerosol. 
Table I: Respiratory Distress Assessment Instrument (From: Lowell DI, Lister G, Von Kloss H, McCarthy P. Wheezing in infants: the response to epinephrine. Pediatrics 1987; 87:939-45.)

\begin{tabular}{|c|c|c|c|c|c|c|c|}
\hline & & & 1 & 2 & 3 & 4 & Maximum Points \\
\hline \multicolumn{8}{|l|}{ Wheezing } \\
\hline Expiration & None & End & $1 / 2$ & $3 / 4$ & All & & 4 \\
\hline Inspiration & None & Part & All & $\ldots$ & $\ldots$ & & 2 \\
\hline Location & None & Segmental & Diffuse & $\ldots$ & $\ldots$ & & 2 \\
\hline \multicolumn{8}{|l|}{ Retractions } \\
\hline Supraclavicular & None & Mild & Moderate & Marked & $\ldots$ & & 3 \\
\hline Intercostal & None & Mild & Moderate & Marked & $\ldots$ & & 3 \\
\hline Subcostal & None & Mild & Moderate & Marked & & & 3 \\
\hline Total & $\ldots$ & $\ldots$ & $\ldots$ & & & & 17 \\
\hline
\end{tabular}

* Within each variable (wheezing, retractions) the subscores are summed to give a total score. The maximum total points for wheezing is 8 and for retractions is 9 .

\section{Data collection}

Baseline demographic data collected at study entry included inclusion and exclusion criteria, age, gender, concomitant medications and other illnesses. The caregiver/parent was asked to describe the child's feeding pattern (normal, less than normal, unable to feed). At the time of study enrolment and then daily (every morning) thereafter the study nurse measured oxygen saturation and wheezing and retractions using the Respiratory Distress Assessment Instrument (Table 1) [13], which was the primary outcome measure of the study. Oxygen saturation was measured using a pulse oximeter (Nellcor Pulse Oximeter, Nellcor Puritan Bennet Inc., Pleasanton, CA) with the infant in a quiet state after breathing room air for at least 10 minutes. If the oxygen saturation went below $85 \%$, the measurement was halted. At the daily assessment, the study nurse interviewed caregivers and reviewed the health record to determine if adverse events were present (vomiting, tremors, pallor), the feeding pattern and recorded the maximum daily heart rate for that 24 hour period.

During the first two study enrolments, it was noted that a bright red nasal discharge was observed in some study participants, and interpreted by bedside nurses as bloody nasal discharge. This discoloration of nasal mucous was found to be a known effect of administration of aerosolized epinephrine, which is caused by the oxidation of the sulphite stabilizer. This effect was not known to the investigators at the time of study design and is not in the drug monograph, but has been reported in a recent trial of epinephrine in the emergency department setting [14]. Because this could lead to unblinding of treatment allocation, an amendment to the study protocol was made for all subsequent patients whereby the bedside nurse wiped the nose of study participants after each study drug administration and immediately before the study nurse performed the daily respiratory assessment.

A nasopharyngeal aspirate for Respiratory Syncytial virus (RSV) antigen was routinely done in participating hospitals to determine appropriate placement for infection control purposes. At the discretion of the attending physician, some children had respiratory tract samples submitted for respiratory virus culture (RSV, influenza, parainfluenza, adenovirus).

A secondary outcome measure was duration of hospital stay, measured using a method previously validated by the Pediatric Investigators Collaborative Network on Infections in Canada studies of hospitalized children with RSV infection [15]. Each day the study nurse assessed which of four reasons accounted for ongoing hospitalization 1) patient receiving drug treatment for bronchiolitis 2) patient receiving oxygen supplementation or parenteral fluids because of bronchiolitis 3) patient hospitalized because of underlying (pre-existing) illness only or 4) awaiting transport home or uncertain home environment. Only those days on which the reason for hospitalization were one or more of receiving medication for bronchiolitis (1) or oxygen supplementation or parenteral fluids because of bronchiolitis (2), were recorded as valid hospital days. Discharge timing, counted as the time the decision was made to discharge home, was at the discretion of the attending physician. Study personnel had no involvement in discharge planning and did not impose any discharge criteria.

All parents/guardians were telephoned seven days after hospital discharge by a research assistant to collect data about the child's convalescence: respiratory symptoms (retractions, wheezing), feeding pattern (normal, less 
than normal, unable to feed), adverse events from medication (shakiness, tremors, pallor," other problems") and whether they had required a visit to a physician or to the emergency department or hospital. The interviewer read closed-ended questions from a standard script.

Adverse events were collected during the hospital stay and during the post-discharge telephone call. The event was described and categorized according to severity (mild, moderate, severe), outcome (recovered fully, recovered with sequelae, ongoing, death) and relationship to study drug (related, probably or possibly related, unrelated, unable to classify). Mild adverse events were defined as "awareness of signs and symptoms, easily tolerated and require no interventions", moderate as "discomfort sufficient enough to interfere with normal activities and/or result in some sort of intervention" and severe as " inability to perform normal activities, distressing and/or incapacitating and definitely require intervention and/or medical attention."

The sample size was calculated to detect a difference in the RDAI score between day one and day three. The estimated sample size for a two-sample comparison of proportions of each group that achieved the four-unit difference was with a probability of type one error of 0.05 and type 2 error of 0.8 was 33 infants per group. The standard deviations were based on previously reported changes in RDAI in bronchiolitis [13].

\section{Analysis}

All randomized children were considered in the analysis. All analyses were performed using SAS 8.02 software (SAS Institute Inc., Cary, USA). Proportions and exact binomial intervals were calculated for discrete variables and comparisons between treatment groups were made using the Fisher's exact test. Summary statistics (mean, median, standard deviation, minimum and maximum) were calculated for continuous variables and comparisons were made between treatment groups using the Wilcoxon ranksum test. Comparisons of trend across time were made using repeated measures analysis of variances. The RDAI was treated as a continuous measure. P-values less than or equal to 0.05 were considered statistically significant.

\section{Results}

Sixty-two children were enrolled with 31 in each treatment arm. Ten were enrolled from the Saint John site and 52 from the Halifax site. All participants completed inhospital follow-up but the parent of one child in the epinephrine group could not be contacted for the oneweek post-discharge telephone call. The mean age of participants was 6.4 months. RSV was identified in nasopharyngeal samples of $81.5 \%$ of children randomized to epinephrine and $78.6 \%$ of those randomized on salbuta- mol. The two groups were similar at baseline; characteristics at enrolment are seen in Table 2. On admission, only $15 \%$ of infants had a normal feeding pattern; $83 \%$ had decreased feeding by parental/caregiver report and $7 \%$ were unable to feed. 245 children were screened who did not enroll: 46 did not meet inclusion criteria and in 34 parents refused consent. The rest were ineligible because of exclusion criteria. The most commons reason for exclusion was previous diagnosis of asthma $(\mathrm{n}=58)$ and previous administration of systemic steroids $(n=44)$.

Racemic epinephrine resulted in a significant improvement in wheezing compared to salbutamol on day $2(\mathrm{p}=$ $0.01)$ and over the entire hospital stay $(\mathrm{p}=0.01)$ (Table 3 ), but not on other days. The total RDAI (wheezing and retractions) in children receiving racemic epinephrine was also significantly better on the second hospital day and over the entire stay $(p=0.02)$. On the third hospital day a significant difference in oxygen saturation was observed in children receiving racemic epinephrine compared to those receiving salbutamol $(96.20 \%$ v. $93.80 \%, 98.80 \mathrm{v}$. $92.00 \mathrm{p}=0.03$ ) but this difference was not significant when the two groups were compared over the entire hospital stay or on other days.

The mean length of stay for children randomized to the racemic epinephrine group was 2.60 days (95\% CI 2.00, $3.20)$ and 3.40 days for those randomized to salbutamol $(95 \%$ CI 2.60, 4.20) ( $p>0.05)$. No significant differences in length of stay or RDAI scores were seen when children confirmed as having RSV infection were compared to those without RSV.

There was no difference in wheezing score, total retraction score, total respiratory score oxygen saturation or duration of stay by study site.

Any adverse event (mild, moderate, severe) was reported in $45.20 \%$ (14/31) of children who received epinephrine compared to $51.60 \%(16 / 31)$ of those who received salbutamol $(\mathrm{p}>0.05)$. There was one severe adverse event (fever greater than $39^{\circ} \mathrm{C}$ rectal), judged unrelated to study medication, which occurred in a child on salbutamol. Tremors and pallor were more common in children receiving racemic epinephrine than in those on salbutamol, but these differences were not statistically significant (19.40\% (6/31) v. $9.70 \%$ (3/31) and $19.40 \%$ (6/31) v. $6.50 \%(2 / 31)$ respectively). Vomiting occurred in $19.4 \%$ $(6 / 31)$ of those receiving epinephrine and $25.8 \%(8 / 31)$ of those on salbutamol; this difference was not statistically significant.

At the follow-up telephone call, one week after discharge over $60 \%$ of infants had at least one ongoing respiratory symptom (Table 4) and most were still not considered to 
Table 2: Characteristics of children less than two years of age admitted to hospital with bronchiolitis by treatment group, at enrolment.

\begin{tabular}{|c|c|c|}
\hline Outcome & Racemic Epinephrine & Salbutamol \\
\hline Male & $45.20 \%$ & $64.50 \%$ \\
\hline Age (median) & 5.49 months & 3.32 months \\
\hline RDAI total & $7.35(95 \% \mathrm{Cl} 6.52,8.19)$ & $8.29(95 \% \mathrm{Cl} 7.24,9.34)$ \\
\hline Wheezing & $4.23(95 \% \mathrm{Cl} 3.60,4.85)$ & $5.06(95 \% \mathrm{Cl} 4.28,5.85)$ \\
\hline Retractions & $3.13(95 \% \mathrm{Cl} 2.64,3.62)$ & $3.23 \%(95 \% \mathrm{Cl} 2.7 \mathrm{I}, 3.74)$ \\
\hline Oxygen saturation (mean) & $94.6 \%$ & $93.5 \%$ \\
\hline Abnormal feeding pattern (less than normal or not feeding) & $90 \%((95 \% \mathrm{Cl} 7.35,97.9)$ & $80 \%(95 \% \mathrm{Cl} 61.4,92.3)$ \\
\hline RSV positive & $81.5 \%(61.9,93.7)$ & $78.6(95 \% \mathrm{Cl} 59,91.7)$ \\
\hline
\end{tabular}

RDAI = Respiratory Distress Assessment Instrument, $\mathrm{Cl}=$ confidence interval

Table 3: Respiratory Distress Assessment Instrument scores by hospital day in children with bronchiolitis randomized to aerosolized racemic epinephrine or salbutamol.

\begin{tabular}{|c|c|c|c|c|c|c|}
\hline \multirow{2}{*}{$\begin{array}{l}\text { Hospital Day } \\
\text { (Number of } \\
\text { children in hospital } \\
\text { for that duration) }\end{array}$} & \multicolumn{2}{|c|}{ Total Wheezing score } & \multicolumn{2}{|c|}{ Retractions } & \multicolumn{2}{|c|}{ Total RDAl score } \\
\hline & $\begin{array}{c}\text { Racemic } \\
\text { epinephrine }\end{array}$ & Salbutamol & $\begin{array}{c}\text { Racemic } \\
\text { epinephrine }\end{array}$ & Salbutamol & $\begin{array}{c}\text { Racemic } \\
\text { epinephrine }\end{array}$ & Salbutamol \\
\hline $0(n=62)$ & 4.23 & 5.06 & 3.13 & 3.23 & 7.35 & 8.29 \\
\hline$I(n=58)$ & 2.04 & 3.70 & 1.64 & 1.64 & 3.68 & 6 \\
\hline $2(n=40)$ & 1.59 & 2.65 & 1.06 & 1.06 & 2.65 & 4.13 \\
\hline $3(n=22)$ & 2.09 & 2.73 & 1.09 & 1.09 & 3.18 & 4.27 \\
\hline $4(n=9)$ & 2.75 & 4.00 & 1.75 & 1.75 & 4.5 & 6.4 \\
\hline $5(n=9)$ & 2.00 & 2.60 & 0.75 & 0.75 & 2.75 & 4.2 \\
\hline
\end{tabular}

be feeding normally by their parents. No statistically significant differences in outcomes at the follow-up phone call were identified.

\section{Discussion}

In this study, treatment of bronchiolitis with aerosolised racemic epinephrine over the course of a child's hospital stay was associated with improvement in respiratory symptoms, but did not result in a statistically significant difference in hospital length of stay. Although previous reports have found that nebulized epinephrine results in short-term clinical improvement in bronchiolitis $[12,16-$ 21], its effect on duration of hospital stay or need for admission is less clear. Two of four randomised clinical trials in the emergency department setting using 1 to 3 doses of epinephrine have found a difference in admission rate $[12,19]$ and two have not $[22,23]$. It is possible that small reductions in length of stay could be detected by larger trials than those conducted thus far. Our study is only the second [24] in which nebulized racemic epinephrine was provided throughout the hospital admission.
Other trials have administered one to three doses spaced on one day only. One might expect that short-term improvement could lead to the clinician's judgement that admission was not necessary. Two [20,21] of four randomised trials $[24,25]$ have suggested that length of stay in hospital is abbreviated in children receiving epinephrine. The subgroup of children that might benefit from this therapy is not clear and larger trials will be necessary to identify if and when administrations of nebulized epinephrine during hospitalisation results in patient benefit. Our study supports the thesis that while airway edema may be improved following administration of racemic epinephrine it is not sustained and does not alter the natural history of bronchiolitis in infants. The inflammatory process initiated by RSV or other respiratory viruses is unaffected and mucous secretion and edema recurs after the effect of epinephrine has dissipated.

We choose salbutamol as a control for epinephrine because it was the local standard of care at the time our trial was designed and it was considered unethical to with- 
Table 4: Prevalence of respiratory symptoms and drug-related adverse events one week after discharge in children randomized to aerosolized racemic epinephrine or salbutamol during their hospital stay for bronchiolitis.

\begin{tabular}{|c|c|c|c|}
\hline \multirow[t]{2}{*}{$\begin{array}{l}\text { Clinical event as reported by } \\
\text { parent or guardian }\end{array}$} & \multicolumn{2}{|c|}{$\begin{array}{c}\text { Percentage of children with symptom at one week post-discharge phone } \\
\text { call (absolute numbers)* }\end{array}$} & \multirow[t]{2}{*}{$\begin{array}{l}\text { P value for comparison of } \\
\text { proportions }\end{array}$} \\
\hline & Racemic epinephrine & Salbutamol & \\
\hline Breathing difficulty & $20.00(6 / 30)$ & $19.4(6 / 31)$ & 1.00 \\
\hline Wheezing & $56.7(17 / 30)$ & $67.7(2|/ 3|)$ & 0.43 \\
\hline Chest retractions & $13.3(4 / 30)$ & $25.8(8 / 31)$ & 0.33 \\
\hline \multicolumn{4}{|l|}{ Feeding pattern: } \\
\hline Normal feeding & $50(15 / 30)$ & $54.8(17 / 31)$ & 0.80 \\
\hline Less than normal & $50(15 / 30)$ & $41.9(\mid 3 / 31)$ & 0.61 \\
\hline Unable to feed & $0(0 / 3 \mathrm{I})$ & $3.2(1 / 31)$ & 1.00 \\
\hline Vomiting & $20(6 / 30)$ & $35.5(11 / 31)$ & 0.25 \\
\hline Tremors & $0(0 / 31)$ & $0(0 / 3 I)$ & N/A \\
\hline Pallor & $13.3(4 / 30)$ & $6.5(2 / 31)$ & 0 \\
\hline Has had a visit to a physician & $23.3(7 / 30)$ & $19.4(6 / 31)$ & 0.42 \\
\hline $\begin{array}{l}\text { Has visited an emergency } \\
\text { department or been hospitalized }\end{array}$ & $3.3(1 / 30)$ & $3.2(1 / 31)$ & 1.00 \\
\hline
\end{tabular}

N/A = not applicable; $*$ Not mutually exclusive

hold a potentially beneficial therapy, even though that benefit was likely minimal [6]. Other randomized trials of epinephrine in hospitalized children have used as the control normal saline [22,25], salbutamol [21] or both [24].

Interestingly we noted a risk to unblinding of treatment allocation early in our trial, by the oxidation of the sulphite preservatives, which turn mucous red or brown in recipients of racemic epinephrine. We implemented measures to avoid unblinding, but could find no mention of this event in previous studies of epinephrine in bronchiolitis. If future trials of racemic epinephrine are conducted, study design should carefully address this possibility and consider using another formulation of epinephrine. Patel et al questioned study personnel and ward staff after completion of their trial and found no difference in the proportion of correct guesses as to allocation by treatment group [24].

Hospital admission for bronchiolitis occurs when the infant has significant respiratory distress or is unable to feed because of the work of breathing. By this point in the evolution of bronchiolitis, lower respiratory tract inflammation is well established and may be difficult to alter. Perhaps for this reason, trials of steroid therapy in infants hospitalized for bronchiolitis have shown no benefit [11]. Length of hospital stay or avoidance of hospital admission is a salient outcome measure for intervention trials of epinephrine because institutional care represents the largest component of direct expenditures (over 60\%) for bronchiolitis [26]. Morbidity associated with bronchiolitis persisted for at least one week after hospital discharge in our population. Reducing costs and morbidity due to bronchiolitis may require more than one intervention, each at specific times during the illness. For example Schuh et al demonstrated a reduction in hospitalization in infants with bronchiolitis treated with dexamethasone (1 $\mathrm{mg} / \mathrm{kg}$ ) in the emergency department [27]. Bisgaard et al demonstrated a reduction in post-RSV symptomatology, principally cough, in infants treated with montelukast within the first week of illness [28]. All of these treatments, if their efficacy were borne out in larger trials, would reduce health care costs associated with this ubiquitous infection. Such studies will need to be large to capture clinically significant outcomes.

Use of racemic epinephrine multiple times over several days was not associated with significant adverse events compared to salbutamol. Epinephrine is a potent adrenergic agonist with potential cardiovascular side effects including tachycardia or bradycardia and hypertension. In the doses used for bronchiolitis such adverse events have not been reported. Given that short-term improvement may occur and its favourable safety profile, it seems reasonable to use aerosolized racemic epinephrine selectively for infants with acute distress to decrease the work of breathing or to avoid assisted ventilation.

\section{Conclusion}

Racemic epinephrine relieves respiratory distress (wheezing, retractions) in infants hospitalized for management of bronchiolitis and is safe but does not abbreviate hospital stay. Morbidity associated with bronchiolitis as identified by parents persists for at least one week after hospital discharge in most infants. 


\author{
Abbreviations \\ Respiratory Distress Assessment Instrument (RDAI)
}

Respiratory Syncytial Virus (RSV)

\section{Competing interests}

The author(s) declare that they have no competing interests.

\section{Authors' contributions}

JML and MBS conceived the study and prepared the protocol. JCL planned the statistical analysis. JCL and PP provided intellectual input to study design. JML drafted the manuscript. JML, MBS and CBO supervised acquisition of study data. HJ conducted the analysis. All authors contributed to interpretation of study results and critically reviewed the manuscript for important intellectual content.

\section{Acknowledgements}

This study was funded by the Nova Scotia Lung Foundation (Legacy Award) and the IWK Health Centre Research Office Research Award, Canada.

Vaponephrine was generously supplied by Aventis Pharma Inc. (Montreal, Canada)

The authors would like to thank the research coordinators Heather Samson, Trish Pottie and Ardith Ambrose and the nurses of the general pediatric floors at the IWK Health Center and Saint John Regional.

\section{References}

I. Wright AL, Taussig LM, Ray CG, Harrison HR, Holberg CJ, The Group Health Medical Associates: The Tucson Children's Respiratory Study II. Lower respiratory tract illness in the first year of life. Am J Epidemiol 1989, I 29: I 232- 1246.

2. McConnochie KM, Roghmann KJ, Liptak GS: Hospitalization for lower respiratory tract illness in infants:variation in rates among counties in New York State and areas within Monroe County. J Pediatr 1995, I 26:220-229.

3. Shay DK, Holman RC, Newman RD, Liu LL, Stout JW, Anderson LJ: Bronchiolitis-associated hospitalizations among US children, 1 980-I 996. Jama 1999, 282: | 440-I 446.

4. Langley JM, LeBlanc JC, Smith B, Wang EE: Increasing incidence of hospitalization for bronchiolitis among Canadian children, 1980-2000. J Infect Dis 2003, 188: 1764-I767.

5. Wickman M, Farahmand BY, Persson PG, Pershagen G: Hospitalization for lower respiratory disease during 20 yrs among under 5 yr old children in Stockholm County: a population based survey. Eur Respir J 1998, I I:366-370.

6. Kellner JD, Ohlsson A, Gadomski AM, Wang EE: Bronchodilators for bronchiolitis. Cochrane Database Syst Rev 2000:CD00I 266.

7. Barr FE, Patel NR, Newth CJL: The pharmacologic mechanism by which inhaled epinephrine reduces airway obstruction in respiratory syncytial virus-associated bronchiolitis. J Pediatr 2000, 16:699-700

8. Wohl ME, Chernick V: State of the art: bronchiolitis. Am Rev Respir Dis 1978, I I 8:759-78I.

9. Hartling L, Wiebe N, Russell K, Patel H, Klassen TP: A meta-analysis of randomized controlled trials evaluating the efficacy of epinephrine for the treatment of acute viral bronchiolitis. Arch Pediatr Adolesc Med 2003, 1 57:957-964.

10. Hartling L, Wiebe N, Russell K, Patel H, Klassen T: Epinephrine for bronchiolitis. Cochrane Database Syst Rev 2004, I:CD003 I 23.

II. King VJ, Viswanathan M, Bordley WC, Jackman AM, Sutton SF, Lohr KN, Carey TS: Pharmacologic treatment of bronchiolitis in infants and children: a systematic review. Arch Pediatr Adolesc Med 2004, I 58:127-137.
12. Menon K, Sutcliffe T, Klassen TP: A randomized trial comparing the efficacy of epinephrine with salbutamol in the treatment of acute bronchiolitis. J Pediatr 1995, I 26: 1004- 1007.

13. Lowell DI, Lister G, Von Koss H, McCarthy P: Wheezing in infants: the response to epinephrine. Pediatrics 1987, 79:939-945.

14. Plint AC, Osmond MH, Klassen TP: The efficacy of nebulized racemic epinephrine in children with acute asthma: a randomized, double-blind trial. Acad Emerg Med 2000, 7:1097-I 103.

15. Wang EEL, Law BJ, Boucher FD, Stephens D, Robinson JL, Dobson S, Langley JM, McDonald J, MacDonald NE, Mitchell I: Pediatric Investigators Collaborative Network on Infections in Canada (PICNIC) study of admission and management variation in patients hospitalized with respiratory syncytial viral lower respiratory tract infection. J Pediatr 1996, I 29:390-395.

16. Sanchez I, De Koster J, Powell RE, Wolstein R, Chernick V: Effect of racemic epinephrine and salbutamol on clinical score and pulmonary mechanics in infants with bronchiolitis. J Pediatr 1993, I22:145-I51.

17. Reijonen T, Korppi M, Pitkakangas S, Tenhola S, Remes K: The clinical efficacy of nebulized racemic epinephrine and albuterol in acute bronchiolitis. Arch Pediatr Adolesc Med 1 995, 149:686-692.

18. Kristjansson S, Lodrup Carlsen KC, Wennergren G, Strannegard IL, Carlsen KH: Nebulised racemic adrenaline in the treatment of acute bronchiolitis in infants and toddlers. Arch Dis Child 1993, 69:650-654.

19. Ray MS, Singh V: Comparison of nebulized adrenaline versus salbutamol in wheeze associated respiratory tract infection in infants. Indian Pediatr 2002, 39: 12-22.

20. Mandelberg A, Tal G, Witzling M, Someck E, Houri S, Balin A, Priel IE: Nebulized $3 \%$ hypertonic saline solution treatment in hospitalized infants with viral bronchiolitis. Chest 2003, I 23:48|-487.

21. Bertrand P, Aranibar H, Castro E, Sanchez I: Efficacy of nebulized epinephrine versus salbutamol in hospitalized infants with bronchiolitis. Pediatr Pulmonol 200 I, 3 I :284-288.

22. Hariprakash S, Alexander J, Carroll W, Ramesh P, Randell T, Turnbull F, Lenney W: Randomized controlled trial of nebulized adrenaline in acute bronchiolitis. Pediatr Allergy Immunol 2003, 14:134-139.

23. Mull CC, Scarfone RJ, Ferri LR, Carlin T, Salvaggio C, Bechtel KA, Trephan MA, Rissman RL, Gracely E): A randomized trial of nebulized epinephrine vs albuterol in the emergency department treatment of bronchiolitis. Arch Pediatr Adolesc Med 2004, 158:113-118.

24. Patel H, Platt RW, Pekeles GS, Ducharme FM: A randomized, controlled trial of the effectiveness of nebulized therapy with epinephrine compared with albuterol and saline in infants hospitalized for acute viral bronchiolitis. J Pediatr 2002, | 4 1:818-824.

25. Wainwright C, Altamirano L, Cheney M, Cheney J, Barber S, Price D, Moloney S, Kimberley A, Woolfield N, Cadzow S, Fiumara F, Wilson P, Mego S, VandeVelde D, Sanders S, O'Rourke P, Francis P: A multicenter, randomized, double-blind, controlled trial of nebulized epinephrine in infants with acute bronchiolitis. $N$ Engl J Med 2003, 349:27-35.

26. Langley JM, Wang EEL, Law BJ, Stephens D, Boucher FD, Dobson S, McDoanlad J, MacDonald NE, Mitchell I, Robinson JL: Economic evaluation of respiratory syncytial virus infection in Canadian children: a Pediatric Investigators Collaborative Network on Infections in Canada (PICNIC) study. J Pediatr 1997. 131:113-117.

27. Schuh S, Coates AL, Binnie R, Allin T, Goia C, Corey M, Dick PT: Efficacy of oral dexamethasone in outpatients with acute bronchiolitis. J Pediatr 2002, I40:27-32.

28. Bisgaard $\mathrm{H}$ : A randomized trial of montelukast in respiratory syncytial virus postbronchiolitis. Am J Respir Crit Care Med 2003, 167:379-383.

\section{Pre-publication history}

The pre-publication history for this paper can be accessed here:

http://www.biomedcentral.com/1471-2431/5/7/prepub 